\title{
Impact of increase in temperature and light intensity on development and metamorphosis of hatchery reared silver pompano Trachinotus blochii (Lacepede, 1801) larvae
}

\author{
R. JAYAKUMAR, M. SAKTHIVEL, A. K. ABDUL NAZAR, G. TAMILMANI, P. RAMESHKUMAR, \\ A. K. SAMAL, K. K. ANIKUTTAN, M. ANBARASU, V. BALAMURUGAN, R. THIAGU, \\ S. SIRAJUDEEN AND G. GOPAKUMAR \\ ICAR-Central Marine Fisheries Research Institute, Mandapam Regional Centre, Mandapam - 623 520, Tamil Nadu, India \\ e-mail:drggopakumar@gmail.com
}

\begin{abstract}
The impact of increase in temperature and light intensity on development and metamorphosis of hatchery produced larvae of silver pompano Trachinotus blochii (Lacepede, 1801) was studied. Two sets of larviculture tanks (Set 1 and Set 2) in triplicate were exposed to two different temperatures and varying light intensities. The growth of the larvae from day one to day 25 post-hatch (dph) and metamorphosis were studied. It was found that an increase of $2^{\circ} \mathrm{C}$ water temperature and increased light intensity significantly reduced the growth. The percentage of growth reduction gradually decreased and got stabilised towards the end of larviculture with a mean reduction of $15 \%$. Further, a delay of three days in metamorphosis was also observed in Set 2. The reduced growth rate coupled with change in pigmentation of larvae can be considered as the resilience response of the larvae to combat temperature and light stress without compromising survival.
\end{abstract}

Keywords: Larval growth, Light intensity, Metamorphosis, Silver pompano, Temperature

Fishes, being poikilotherms, are directly influenced by changes in environmental parameters of the surrounding water. Among the ecological factors, water temperature is vital especially during embyrogenesis and larval development of marine fishes (Aldanondo et al., 2008; Guan et al., 2008; Villamizar et al., 2009; Blanco-Vives et al., 2010; Ostrowski et al., 2011; Villamizar et al., 2011). The anticipated seawater temperature rise due to climate change in future years can adversely affect the eggs and larvae of many species of fishes. Hence, it is probable that some of the existing commercial fisheries also may get affected due to climate change. In this context, selection of species having larvae with resilience for elevated temperature will be useful for development of farming practices which would be necessary for compensating the anticipated scarcity of fish due to climate change.

The silver pompano Trachinotus blochii (Lacepede, 1801) is one of the suitable candidate fish species for marine and brackishwater aquaculture due to its fast growth rate, good meat quality, high market demand and good adaptability to different farming environments (Jayakumar et al., 2014). Realising the potential of the species for farming, the ICAR-Central Marine Fisheries
Research Institute (ICAR-CMFRI), at its Mandapam Regional Centre, prioritised this species for captive breeding and seed production. The species was selected for investigating the effect of increased temperature and light intensity on development and metamorphosis of hatchery produced silver pompano.

Newly-hatched larvae obtained from the same brood of T. blochii were collected from the hatchery for the study. Rectangular fibre reinforced plastic (FRP) tanks (yellow colour) of $2 \mathrm{t}$ capacity with $1 \mathrm{t}$ filtered seawater were used. Approximately 5000 nos. of larvae were stocked in each tank at a stocking density of 5 larvae per litre. The larval rearing protocols were followed as per Nazar et al. (2012).

Set 1 tanks in triplicate was considered as control and were placed in the hatchery in such a way that they were not exposed to direct sunlight and the impact of sunlight was minimal. The second set of tanks (Set 2) in triplicate were placed in the hatchery exposed to direct sunlight for the entire day. The larvae were stocked in both the sets of tanks on first day post-hatch (dph). The study was carried out upto $25 \mathrm{dph}$ which is the actual larviculture period.

A random sample of 10 larvae were collected from each tank (30 larvae per set) and placed in a beaker at 15:00 hrs every day. Larvae anesthetised with MS-222 
(200-300 mg 1-1, Rombough, 2007) were observed under a stereozoom microscope equipped with an eyepiece micrometer. Colour of the larvae was observed from a clear contrasting background and total length (nearest to $0.01 \mathrm{~mm}$ ) of the larvae were also measured. The larvae sampled were not returned to their original tanks after measurements to avoid handling related mortality.

Temperature $\left({ }^{\circ} \mathrm{C}\right)$ and light intensity (Lux) were recorded at regular intervals twice daily during the entire study. Growth/development was recorded daily in terms of total length of the larvae. Data on larval length were analysed with univariate general linear model and the data on larval colour with multinomial logistic regression. The statistical analyses were carried out using the SPSS 20.0 statistical package (SPSS Inc., USA).

Results of the observation are presented in Table 1. The mean daily temperature recorded in Set 1 and Set 2 tanks were $29.0 \pm 0.2$ and $31.0 \pm 0.2$, respectively. The light intensity ranged from 1910 to $4450 \mathrm{~lx}$ and 2200 to $71601 x$ in Set 1 and Set 2 tanks respectively. All the other parameters and feeding schedule were kept at optimum levels in both set of tanks. Statistical analysis revealed that temperature and light intensity together had high significant effect $(\mathrm{p}<0.01)$ on growth as well as change in pigmentation of the larvae. Average increase of $2^{\circ} \mathrm{C}$ in water temperature and increased light intensity in Set 2 resulted in reduced growth of about 10 to $33 \%$ from $7 \mathrm{dph}$ to $12 \mathrm{dph}$. Subsequently, the reduction percentage gradually decreased and stabilised at around 15\% from 21 dph onwards. The overall reduction of growth in terms of length at the end of the study was $15 \%$ in Set 2 . It was observed that the maximum reduction of length due to stress induced by high temperature and light was in the mid phase of larviculture period i.e., 10 to $15 \mathrm{dph}$. After $15 \mathrm{dph}$ the percentage of reduction gradually decreased and got stabilised which indicates the resilience of the species (Fig. 1). Metamorphosis was observed on 18 and $21 \mathrm{dph}$ in Set 1 and Set 2, respectively. A delay of three days was noted in metamorphosis of Set 2 fishes compared to Set 1. The pattern of larval pigmentation in Set 2 was observed to vary from translucent white ( 8 to $14 \mathrm{dph}$ ) to brown (15 to $20 \mathrm{dph}$ ) eventually to silver (21 dph onwards) compared to the pigmentations in Set 1 which remained black all through the larval phase till metamorphosis (Fig. 2a to f). The number of larvae that survived at the end of study was same in both the sets.

Table 1. Mean length (mm) and pigmentation of silver pompano larvae under different temperature $\left({ }^{\circ} \mathrm{C}\right)$ and light intensities (lux)

\begin{tabular}{|c|c|c|c|c|c|c|}
\hline \multirow{2}{*}{ Age (dph) } & \multicolumn{2}{|c|}{ Light intensity } & \multicolumn{2}{|c|}{ Mean length (mm) } & \multicolumn{2}{|c|}{ Pigmentation } \\
\hline & Set 1 & Set 2 & $29.0 \pm 0.2^{\circ} \mathrm{C}($ Set 1$)$ & $31.0 \pm 0.2^{\circ} \mathrm{C}($ Set 2$)$ & $29.0 \pm 0.2^{\circ} \mathrm{C}($ Set 1$)$ & $31.0 \pm 0.2^{\circ} \mathrm{C}($ Set 2$)$ \\
\hline 1 & 2720 & 2964 & $2.35 \pm 0.02$ & $2.35 \pm 0.02$ & Black & Black \\
\hline 2 & 2681 & 3063 & $2.43 \pm 0.03$ & $2.44 \pm 0.03$ & Black & Black \\
\hline 3 & 2695 & 3428 & $2.55 \pm 0.02$ & $2.60 \pm 0.03$ & Black & Black \\
\hline 4 & 2713 & 3110 & $3.13 \pm 0.07$ & $3.05 \pm 0.05$ & Black & Black \\
\hline 5 & 2639 & 3315 & $3.23 \pm 0.13$ & $3.35 \pm 0.15$ & Black & Black \\
\hline 6 & 2698 & 3480 & $3.88 \pm 0.06$ & $3.71 \pm 0.15$ & Black & Black \\
\hline 7 & 2629 & 3185 & $4.26 \pm 0.09$ & $3.85 \pm 0.07$ & Black & Black \\
\hline 8 & 2672 & 3575 & $5.16 \pm 0.03$ & $4.04 \pm 0.16$ & Black & White \\
\hline 9 & 2559 & 2385 & $5.67 \pm 0.03$ & $4.26 \pm 0.15$ & Black & White \\
\hline 10 & 2525 & 2314 & $6.36 \pm 0.12$ & $4.39 \pm 0.20$ & Black & White \\
\hline 11 & 2333 & 2290 & $7.07 \pm 0.09$ & $4.81 \pm 0.19$ & Black & White \\
\hline 12 & 2479 & 2202 & $8.07 \pm 0.09$ & $5.38 \pm 0.23$ & Black & White \\
\hline 13 & 3808 & 2309 & $8.33 \pm 0.35$ & $6.25 \pm 0.27$ & Black & White \\
\hline 14 & 4450 & 5486 & $9.57 \pm 0.33$ & $6.79 \pm 0.38$ & Black & White \\
\hline 15 & 2575 & 4993 & $10.70 \pm 0.26$ & $7.53 \pm 0.45$ & Black & Brown \\
\hline 16 & 2099 & 5486 & $11.60 \pm 0.51$ & $8.40 \pm 0.48$ & Black & Brown \\
\hline 17 & 2147 & 2566 & $12.50 \pm 0.62$ & $9.30 \pm 0.55$ & Black & Brown \\
\hline 18 & 2126 & 2596 & $13.30 \pm 0.67$ & $10.39 \pm 0.75$ & Silver & Brown \\
\hline 19 & 1912 & 2808 & $14.30 \pm 0.49$ & $11.30 \pm 0.81$ & Silver & Brown \\
\hline 20 & 2100 & 2894 & $15.00 \pm 0.60$ & $12.50 \pm 0.85$ & Silver & Brown \\
\hline 21 & 2059 & 7158 & $15.90 \pm 0.65$ & $13.30 \pm 0.89$ & Silver & Silver \\
\hline 22 & 2024 & 2681 & $17.10 \pm 0.69$ & $14.50 \pm 0.95$ & Silver & Silver \\
\hline 23 & 2912 & 4772 & $18.20 \pm 0.78$ & $15.40 \pm 1.04$ & Silver & Silver \\
\hline 24 & 4250 & 2605 & $19.30 \pm 0.71$ & $16.50 \pm 1.03$ & Silver & Silver \\
\hline 25 & 3522 & 4790 & $21.40 \pm 0.53$ & $18.10 \pm 1.12$ & Silver & Silver \\
\hline
\end{tabular}




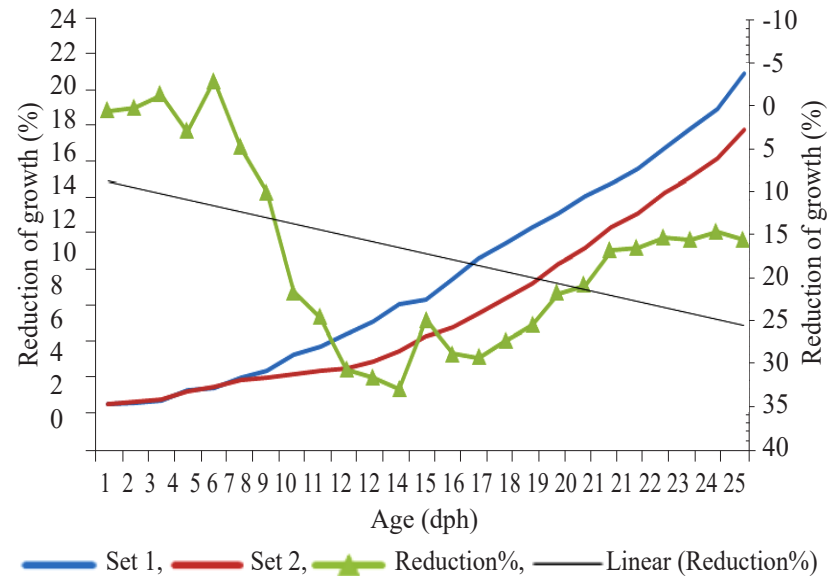

Fig. 1. Total length $(\mathrm{mm})$ and \% reduction of growth in silver pompano larvae (1 to $25 \mathrm{dph}$ ) at different temperature regimes (Set 1 and Set 2) Straight line indicate trend of reduction

Larval stages of marine finfishes are sensitive to environmental parameters (Berlinsky et al., 2004; Yefera and Darias, 2007; Shi et al., 2010). Among the most critical external factors in the early ontogeny of fish are photoperiod, temperature and salinity (Hart et al., 1996; Boeuf and Bail, 1999; Kamler, 2002). Temperature affects virtually all the aspects of early larval development (Rombough, 1996; Fielder et al., 2005; Wen et al., 2013), such as the efficiency of yolk absorption and utilisation (Hart and Purser, 1995; Hardy and Litvak, 2004; Sakthivel et al., 2016), time to first feeding rate and growth (Hart and Purser, 1995; Berlinsky et al., 2004), survival (Gadomski and Cadell, 1991; Bidwell and Howell, 2001; Berlinsky et al., 2004; Wexler et al., 2011) and the behaviour as well as swimming speed (Johnston and Mathias, 1994).

Silver pompano is known for growing well in low salinities and having good adaptability to different farming environments (Gopakumar et al., 2012; Kalidas et al., 2012; Nazar et al., 2012). In the present investigation it was found that the growth and metamorphosis of silver pompano larvae got significantly affected by the temperature and light in earlier stages. A significant reduction in growth of larvae was observed when the temperature was higher and the reduction was maximum during the larval stages between 10 and $15 \mathrm{dph}$ and thereafter, the reduction in growth was less conspicuous. The reduction of growth can be attributed to the stress induced by higher temperature and light, which was more pronounced in the initial days of exposure. As the larvae exhibited resilience to the conditions, reduction in growth gradually declined and got stabilised towards the end of larviculture period. It is evident that the larvae had inherent capacity to combat stress caused by higher temperature and light intensity.

The newly-hatched larvae of silver pompano are usually black in colour and become silvery as they grow and metamorphose (Nazar et al., 2012). A conspicuous variation of pigmentation was observed in the second set

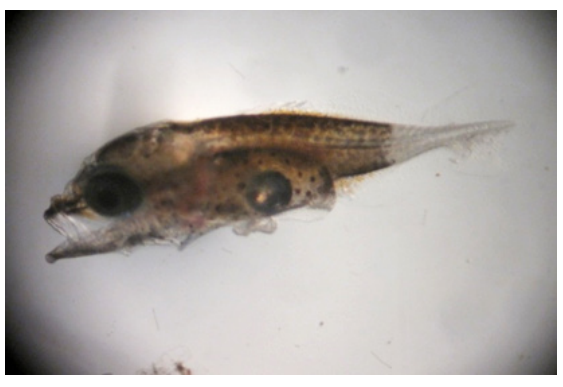

(a1)

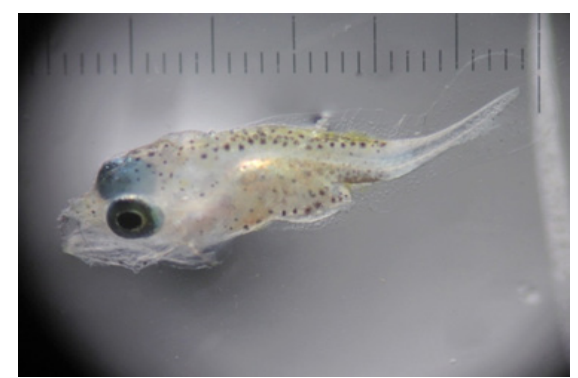

(b1)

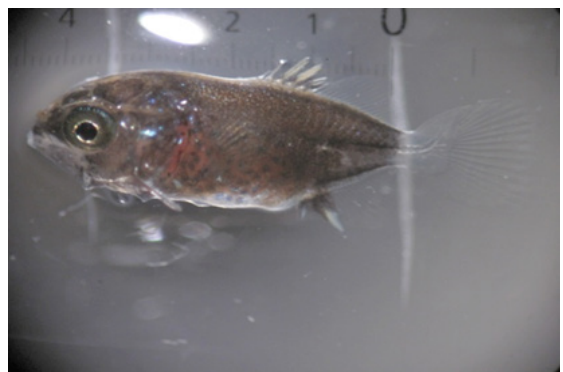

(a2)

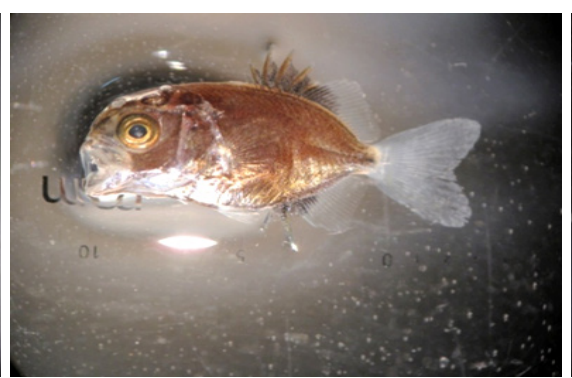

(b2)

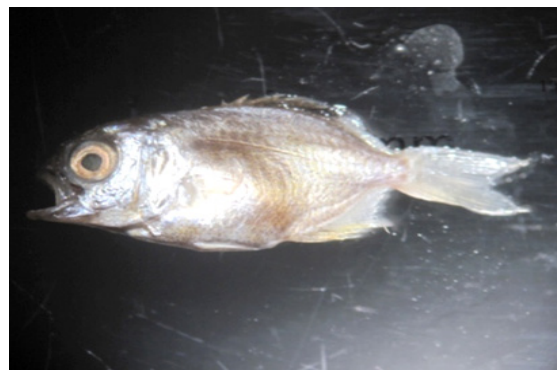

(a3)

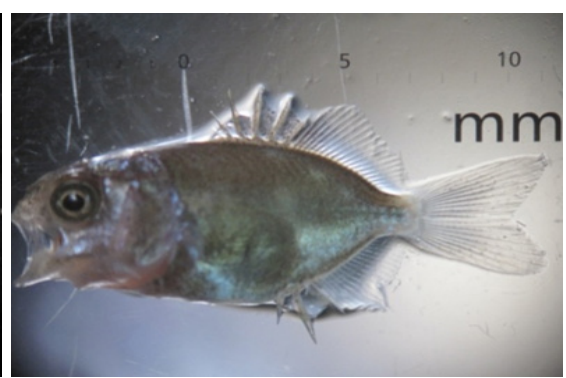

(b3)

Fig. 2. Variation in pigmentation of silver pompano larvae observed at different temperatures

Larvae in Set $1\left(29 \pm 0.2^{\circ} \mathrm{C}\right)$ : (a1) 8 dph (black); (a2) 15 dph (black); (a3) Metamorphosed larvae at 22 dph (silvery) Larvae in Set $2\left(31 \pm 0.2^{\circ} \mathrm{C}\right)$ : (b1) 8 dph (translucent white); (b2) 15 dph (brown); (b3) Metamorphosed larvae at 22 dph (silvery) 
from $8 \mathrm{dph}$ and all the larvae appeared translucent white whereas the larval pigmentation continued to be black in the control. However, the whitened larvae showed normal movement and feeding behaviour. It is evident that the change in pigmentation might be due to the temperature and light induced physiological changes. The appearance of original silvery colour at the end of larviculture period in Set 2 implies that the larvae had the resilience to combat stress. The reduced growth rate coupled with change of pigmentation of the larvae and delay in metamorphosis in response to high temperature and light intensity can be taken as an adaptive strategy of the larvae to combat stress. It is also evident that the larvae had resilience to overcome the adverse temperature conditions without affecting survival. It is felt that the resilience to adverse environmental parameters in the larval stage itself is very much advantageous for selecting the species for coastal aquaculture in the anticipated scenario of climate change. However, further detailed studies are needed to clarify the impact of various environmental parameters on the larval stages.

\section{Acknowledgements}

The authors wish to acknowledge the funding support from the ICAR Research Project, National Innovations on Climate Resilient Agriculture (NICRA). They also wish to acknowledge the constant encouragement from Dr. G. Syda Rao, former Director, and Dr. A. Gopalakrishnan, Director, ICAR-CMFRI, Kochi.

\section{References}

Aldanondo, N., Cotano, U., Etxebeste, E., Irigoien, X., Alvarez, P., Martinez de Murguia, A. and Herrero, D. L. 2008. Validation of daily increments deposition in the otoliths of European anchovy larvae (Engraulis encrasicolus L.) reared under different temperature conditions. Fish. Res., 93: 257-264.

Berlinsky, D. L., Taylor, J. C., Howell, R. A., Bradley, T. M. and Smith, T. I. J. 2004. The effects of temperature and salinity on early life stages of black sea bass Centropristis striata. J. World Aquacult. Soc., 35: 335-344.

Bidwell, D. A. and Howell, W. H. 2001. The effect of temperature on first feeding, growth and survival of larval witch flounder Glyptocephalus cynoglossus. J. World Aquacult. Soc., 32: 373-384.

Blanco-Vives, B., Villamizar, N., Ramos, J., Bayarri, M. J., Chereguini, O. and Sanchez-Vazquez, F. J. 2010. Effect of daily thermo-and photo-cycles of different light spectrum on the development of Senegal sole (Solea senegalensis) larvae. Aquaculture, 306: 137-145.

Boeuf, G. and Bail, P. L. 1999. Does light have an influence on fish growth? Aquaculture, 177: 129-152.

Fielder, D. S., Bardsley, W. J., Allan, D. L. and Pankhurst, P. M. 2005. The effects of salinity and temperature on growth and survival of Australian snapper, Pagrus auratus larvae. Aquaculture, 250: 201-214.

Gadomski, D. M. and Cadell, S. M. 1991. Effects of temperature on early-life stages of California halibut Paralichthys californicus. Fish. Bull., 89: 567-576.

Gopakumar, G., Nazar, A. K. A., Jayakumar, R., Tamilmani, G., Kalidas, C., Sakthivel, M., Rameshkumar, P., Rao, G. H., Premjothi, R., Balamurugan, V., Ramkumar, B., Jayasingh, M. and Rao, G. S. 2012. Broodstock development through regulation of photoperiod and controlled breeding of silver pompano, Trachinotus blochii (Lacepede, 1801) in India. Indian J. Fish., 59: 53-57.

Guan, L., Snelgrove, P. V. R. and Gamperl, A. K. 2008. Ontogenetic changes in the critical swimming speed of Gadus morhua (Atlantic cod) and Myoxocephalus scorpius (shorthorn sculpin) larvae and the role of temperature. J. Exp. Mar. Biol. Ecol., 360: 31-38.

Hardy, R. S. and Litvak, M. K. 2004. Effects of temperature on the early development, growth and survival of shortnose sturgeon Acipenser brevirostrum and Atlantic sturgeon Acipenser oxyrhynchus yolk-sac larvae. Environ. Biol. Fish., 70: 145-154.

Hart, P. R. and Purser, G. J. 1995. Effects of salinity and temperature on eggs and yolk sac larvae of the greenback flounder (Rhombosolea tapirina Gunther, 1982). Aquaculture, 136: 221-230.

Hart, P. R., Hutchinson, W. G. and Purser G. J. 1996. Effects of photoperiod, temperature and salinity on hatchery-reared larvae of the greenback flounder (Rhombosolea tapirina Gunther, 1862). Aquaculture, 144: 303-311.

Jayakumar, R., Abdul Nazar, A. K., Tamilmani, G., Sakthivel, M., Kalidas, C., Rameshkumar, P., Hanumanta Rao, G. and Gopakumar, G. 2014. Evaluation of growth and production performance of hatchery produced silver pompano Trachinotus blochii (Lacepede, 1801) fingerlings under brackishwater pond farming in India. Indian J. Fish., 61: 58-62.

Johnston, T. A. and Mathias, J. A. 1994. The effects of temperature on feeding in zooplanktivorous walleye Stizostedion vitreum larvae. Environ. Biol. Fish., 40: 189-198.

Kalidas, C., Sakthivel, M., Tamilmani, G., Rameshkumar, P., Nazar, A. K. A., Jayakumar, R., Balamurugan, V., Ramkumar, B., Premjothi, R. and Gopakumar, G. 2012. Survival and growth of juvenile silver pompano Trachinotus blochii (Lacepède, $1801)$ at different salinities in tropical conditions. Indian J. Fish., 59: 95-98.

Kamler, E. 2002. Ontogeny of yolk-feeding fish: an ecological perspective. Rev. Fish Biol. Fish., 12: 79-103.

Nazar, A. K. A., Jayakumar, R., Tamilmani, G., Sakthivel, M., Kalidas, C., Rameshkumar, P., Anbarasu, M., Sirajudeen, S., Balamurugan, V., Jayasingh, M. and Gopakumar. G. 2012. Larviculture and seed production of the silver pompano, 
Trachinotus blochii (Lacepede, 1801) for the first time in India. Indian J. Fish., 59: 83-87.

Ostrowski, A. D., Watanabe, W. O., Montgomery, F. P., Rezex, T. C., Shafer, T. H. and Morris Jr, J. A. 2011. Effect of salinity and temperature on the growth, survival, whole body osmolality and expression of $\mathrm{Na}^{+} / \mathrm{K}^{+}$ATPase mRNA in red porgy (Pagrus pagrus) larvae. Aquaculture, 314: 193-201.

Rombough, P. J. 1996. The effects of temperature on embryonic and larval development. In: Wood, C. M. and Mc Donald, D. G. (Eds.), Society forExperimental Biology Seminar Series 61: Global warming implications for freshwater and marine fish. Cambridge University Press, UK, p. 177-223.

Rombough, P. J. 2007. Ontogenetic changes in the toxicity and efficacy of the anaesthetic MS222 (Tricaine methanesulfonate) in zebrafish (Danio rerio) larvae. Comp. Biochem. Physiol. A., 148: 463-469.

Sakthivel, M., Jayakumar, R., Abdul Nazar, A. K., Tamilmani, G., Rameshkumar, P., Kalidas, C., Anbarasu, M. Balamurugan, V., Thiagu, R., Sirajudeen, S. and Gopakumar, G. 2016. Effect of temperature on yolk sac utilisation and growth of newly hatched larvae of cobia, Rachycentron canadum (Linnaeus, 1766). Indian J. Fish., 63: 135-139.
Shi, Y., Zhang, G., Zhu, Y. and Liu, J. 2010. Effects of photoperiod, temperature and salinity on growth and survival of obscure puffer Takifugu obscurus larvae. Aquaculture, 309: 103-108.

Villamizar, N., Garcia-Alcazar, A. and Sanches-Vazaues, F. J. 2009. Effect of light spectrum and photoperiod on the growth, development and survival of European sea bass (Dicentrarchus labrax) larvae. Aquaculture, 292 (1-2): 80-86.

Villamizar, N., Garcia-Mateos, G. and Sanches-Vazques, F. J. 2011. Behavioural responses of European sea bass (Dicentrarchus labrax) larvae and Artemia sp. exposed to constant light or darkness vs. light/dark cycles of white, red or blue wavelength. Aquaculture, 317: 197-202.

Wen, W., Huang, X., Chen, Q., Feng, L. and Wei, L. 2013. Temperature effects on early development and biochemical dynamics of a marine fish, Inimicus japonicas. J. Exp. Mar. Biol. Ecol., 442: 22-29.

Wexler, J. B., Margulies, D. and Scholey, V. P. 2011. Temperature and dissolved oxygen requirements for survival of yellow fin tuna, Thunnus albacares, larvae. J. Exp. Mar. Biol. Ecol., 404: 63-72.

Yefera, M. and Darias M. J. 2007. The onset of exogenous feeding in marine fish larvae. Aquaculture, 268: 53-63. 